\title{
AS RELAÇÕES DE INTERTEXTUALIDADE CONFORME AS FUNÇÕES DISCURSIVAS ANAFÓRICAS DIRETAS NO GÊNERO DIGITAL COMENTÁRIO, NO FACEBOOK
}

\author{
THE INTERTEXTUAL RELATIONS ACCORDING TO THE DIRECT ANAPHORIC \\ DISCURSIVE FUNCTIONS IN THE DIGITAL GENRE COMMENT, ON FACEBOOK
}

\author{
Maria Teresa Tedesco V. Abreu \\ Universidade do Estado do Rio de Janeiro, Brasil \\ teresatedesco@uol.com.br \\ Cristina Normandia dos Santos \\ Universidade do Estado do Rio de Janeiro, Brasil \\ crnormandia@yahoo.com.br
}

RESUMO: Recente estudo sobre o nível microdiscursivo e o nível macrodiscursivo do gênero digital comentário, na rede social Facebook, comprovou que esse gênero é uma superestrutura discursiva. Pautado na análise de funções discursivas de Tedesco (2002) de expressões anafóricas diretas, foi possível constatar em sequências textuais do gênero digital comentário o fenômeno da intertextualidade, propriedade de coerência textual. A intertextualidade é uma propriedade reconhecida em hipertextos. No entanto, observa-se que abordagens sobre a intertextualidade em hipertextos, especificamente na Internet, são deficitários por não exemplificarem como a propriedade de coerência é desenvolvida em gêneros digitais. Neste sentido, o presente artigo tem o objetivo de discutir a intertextualidade e suas particularidades discursivas a partir das funções discursivas de expressões anafóricas diretas em textos verbais de comentários publicados em perfil público da jornalista Eliane Cantanhêde. As expressões anafóricas diretas apresentam significativa função coesiva em textos verbais, as quais são estratégias textuais e cognitivas que muito contribuem para a produção de sentidos do texto e, assim, refletem que a instabilidade dos objetos no uso da linguagem. Essa é uma abordagem fundamentada na Linguística Textual, a qual apresenta a concepção de língua com uma atividade de interação que pressupõe a existência do sujeito social.

PALAVRAS-CHAVE: intertextualidade; funções anafóricas; gênero discursivo comentário; Facebook.

ABSTRACT: Recent study on the micro-discursive and the macro-discursive levels of the digital genre comment, on the social network Facebook, proved that this genre is a discursive superstructure. Based on the analysis of discursive functions of Tedesco (2002) of direct anaphoric expressions, it was possible to verify the intertextuality phenomenon in text sequences of the digital genre comment, property of textual coherence. Intertextuality is a property recognized in hypertexts. However, it is observed that approaches on intertextuality in hypertexts, specifically on the Internet, are deficient because they do not exemplify how coherence property is developed in digital genres. In this sense, this article aims at discussing intertextuality and its discursive particularities from the discursive functions of direct anaphoric expressions in verbal texts of comments published in the public profile of the journalist Eliane Cantanhêde. The direct anaphoric expressions 
present a significant cohesive function in verbal texts, which are textual and cognitive strategies that contribute much to the production of meanings of the text and thus reflect that the instability of objects in the use of language. This is an approach based on Textual Linguistics, which presents the concept of language with an interaction activity that presupposes the existence of the social subject.

KEYWORDS: intertextuality; anaphoric functions; discursive genre comment; Facebook.

\section{Considerações iniciais}

O presente artigo visa discutir as relações linguística-discursivas em textos verbais do gênero digital comentário, no suporte Facebook, rede social utilizada para fins pessoais e públicos que apresenta um número expressivo de usuários no mundo. Especificamente, o artigo tratará das funções discursivas de expressões anafóricas diretas (TEDESCO, 2002), que se encontram situadas no nível microdiscursivo, as quais revelam relações de intertextualidade, uma das propriedades que contribuem para a coerência textual. A função discursiva de expressões anafóricas diretas e a intertextualidade são dados que comprovam que o gênero digital comentário é uma superestrutura discursiva.

Para esse fim, o artigo, na primeira seção, aborda a respeito das mudanças culturais que a sociedade experimenta com o uso da linguagem na Internet. Em seguida, a segunda seção vai abordar sobre a função discursiva do gênero digital comentário como contrapartida de textos-fonte, aspecto que demonstra a formação de pares metatextuais, como desdobramento da discussão de Genette (2010).

A compreensão da função discursiva do gênero digital comentário dá condições para abordagem das funções discursivas de expressões anafóricas diretas e suas implicações intertextuais, conforme a terceira seção deste estudo. Ao final, são apresentadas as considerações finais e as referências bibliográficas, encerrando 0 presente diálogo sobre a interação da linguagem em gênero digital do Facebook.

\section{A influência cultural do uso virtual da linguagem}

O entretenimento na Internet criou na sociedade sentimentos de êxtase, de curiosidade e de desconfiança. Tais sentimentos refletem que a mídia digital, que, em 2019, completa 30 anos de existência, está enraizada nas práticas sociais de linguagem dos indivíduos.

O sentimento de êxtase é fruto da percepção da mídia digital como um meio rápido e simples para a comunicação tanto com objetivos pessoais quanto com objetivos profissionais, possibilitada pelo constante desenvolvimento de tecnologias de informação, a partir da criação de ferramentas digitais como computadores, tablets, smartphones, Iphones, entre outros. Suportes tecnológicos que dão acesso à Internet e que possibilitam as comunicações pessoais, para o trabalho, para o entretenimento, para serviços de ordem pessoal, pública, política e religiosa (CASTELLS, 1999), entre outras, pois, a comunicação é a base da interação social.

O sentimento de curiosidade em relação à mídia digital está na mudança considerável no modo como a informação é processada na sociedade. A informação na 
idade digital passa a ser processada de forma coletiva, compartilhada, em rede. Uma transformação cultural, porque a sociedade estava habituada ao processamento da informação desenvolvida de maneira centralizada, conforme ocorre nos meios de comunicação de massa tradicionais: o rádio, a televisão e os jornais impressos. Esses tinham a exclusividade da propagação da informação, por isso, o lugar centralizado. Logo,

À medida que se apropriaram de novas formas de comunicação, as pessoas construíram seus próprios sistemas de comunicação em massa, via SMS, blogs, vlogs, podcasts, wikis e coisas do gênero. [...] Novas formas de auto-comunicação em massa surgiram da engenhosidade de jovens usuários que se transformaram em produtores (CASTELLS, 1999, p. XII).

As recentes formas de auto-comunicação de massa - SMS, blogs, Facebook, Twitter - atraem o interesse das pessoas, como os jovens, porque as mesmas dão liberdade para a criação de canais de informações, além de permitirem uma relação coletiva com pessoas conhecidas e desconhecidos que partilham de interesses semelhantes, assim, sendo formadas as redes sociais. Lévy (2010) ressalta que foram os jovens os responsáveis pelo crescimento da Internet, porque os mesmos apresentaram e normalmente apresentam - a predisposição "para experimentar, coletivamente, formas de comunicação diferentes daquelas que as mídias clássicas nos propõem" (LÉVY, 2010, p. 11), como Castells (1999) também enfatizou.

Neste contexto atual, observa-se que qualquer usuário da língua pode criar seu canal de informação e realizar o entretenimento de fatos, o que tira dos profissionais da área jornalística, por exemplo, o monopólio da informação. Tal aspecto mudou o comportamento do contexto jornalístico, pois, de acordo com Castells (1999, p.XII), "Os jornais se transformaram em organizações estruturadas internamente em rede e conectadas globalmente a redes de informação na internet". Portanto, as redes sociais, na Internet, são, atentamente, acompanhadas pelos meios jornalísticos e por aqueles que os compõem. É comum fatos serem noticiados primeiro nas redes sociais, para em seguida estarem na mídia televisiva e em outras mídias de massa. Um exemplo disso foi a morte de cantor americano Michael Jackson, em 2008. A morte do cantor pop foi compartilhada, primeiro, em redes sociais e, em seguida, em outras mídias de massa.

Outro aspecto relevante da auto-comunicação de massa na Internet é a liberdade de exposição da opinião, que pode ocorrer pelo texto verbal, pelo texto não-verbal, pelo texto sonoro e pelo texto híbrido que contempla as três especificações de texto. Neste aspecto, destaca-se o gênero discursivo digital comentário, o qual circula em redes sociais como o popular Facebook, e é definido como uma superestrutura discursiva, que explicita o uso da linguagem em ambiente hipertextual.

Esta transformação no processamento da informação produziu a desconfiança de áreas relacionadas com a ciência humana. Especificamente, a sociologia, a filosofia, a educação e a linguagem. As três primeiras se debruçam em discutir o aprofundamento da exclusão social e as mudanças culturais com o uso da comunicação digital. Neste ponto de vista, Sodré (2006, p. 22) diz:

Hoje, o processo redunda numa mediação social exacerbada, a midiatização, com espaço próprio e relativamente autônomo em face das formas interativas presentes nas mediações tradicionais. [...] o indivíduo é solicitado a viver, muito 
pouco auto-reflexivamente, no interior das tecnomediações, cujo horizonte comunicacional é interatividade absoluta.

Logo, a diminuição da autorreflexão é um aspecto negativo da comunicação digital que pode ser exemplificada com a proliferação de textos com conteúdos falsos, os quais são compartilhados e, geralmente, são comentados e curtidos pelos interactantes em redes sociais, por causa, exatamente, da diminuição da autorreflexão do processo de interatividade absoluta ressaltada por Sodré (2006).

Estas transformações no processamento da comunicação digital foram também inquietantes para os estudos de linguagem. Os textos verbais que estruturavam comentários, chats, e-mails, entre outros gêneros digitais determinaram reflexões que discutiam se estes textos verbais são vinculados à prática social da escrita ou à prática social da fala.

Estudiosos como Marcuschi e Xavier (2010) propõem que o uso virtual da língua, conforme os gêneros digitais, é, essencialmente, a prática da linguagem escrita. Uma prática social da escrita condizente com o contexto digital e com o propósito comunicativo de interactantes, o que justifica as variações neste uso da língua (MARCUSCHI, 2003). Em parte, a presente discussão se harmoniza com esta percepção.

Afiliados com a percepção prescritiva, também, consideram o uso virtual da linguagem relacionado com a escrita. No entanto, fundamentado no conceito dicotômico que determina especificidades para a escrita e para fala (MARCUSCHI, 2003), nesse sentido não se considera a variação, conforme o processo continuum da linguagem. Logo, a suposta escrita em gêneros digitais viola o padrão culto da língua escrita, com desvios linguísticos, os quais refletem a fala (POSSENTI, 2009).

Verificam-se duas percepções distintas a respeito do uso da língua na Internet. Entretanto, a percepção da variação vai ao encontro da Linguística textual, que determina a existência do sujeito social, o qual interage pela linguagem $(\mathrm{KOCH}, 2002)$. São diversas atividades de interação pela linguagem que a língua sofre as variações, conforme 0 contexto de uso e o propósito comunicativo. Isso explica as particularidades do uso da língua nos gêneros digitais e, neste sentido, dá condições de elucubrar a terceira modalidade da linguagem, como propõe Tedesco (2013, p. 480):

\begin{abstract}
A interação, portanto, é a essência da comunicação, "do se querer dizer". Logo, as redes sociais, um dos tipos de esferas sociais existentes, exemplificam de forma plena esse processo. Cada esfera social terá seu tipo de enunciado; a esfera do trabalho tem seus enunciados específicos, assim como a escola, as artes, as ciências, as leis, as tecnologias, a internet e as redes sociais, de modo geral. Se existe uma ampliação dessas formas de comunicação, inclusive considerando os diferentes suportes, postula-se a possibilidade de reestruturação do que sejam as modalidades da língua.
\end{abstract}

A reestruturação a respeito das modalidades da língua está fundamentada na percepção teórica que afirma a existência do continuum entre as práticas sociais da linguagem - a fala e a escrita. Deste modo, o uso da linguagem nas atividades de entretenimento da Internet vai apresentar as particularidades do uso da linguagem da modalidade oral e da modalidade escrita como a informalidade e a maior aproximação da fala quanto a presença da pontuação e da interação à distância da escrita (TEDESCO, 2013). Além de traços particulares do uso da linguagem na Internet como: os recursos 
não lexicalizados, suprassegmentais, paralinguísticos (na Internet, os paralinguísticos são os emoticons). Tais particularidades dão identidade para o uso virtual da língua na Internet, condizente com a prática interativa e coletiva do meio digital.

O que se defende é que estamos diante de um uso da linguagem que contempla não somente o texto verbal, mas também o texto não verbal, o texto sonoro e o texto híbrido, que é a convergência das outras tipificações textuais. Logo, concorda-se parcialmente com Marcuschi (2003) quando o mesmo pontua para o processo de variação da língua. Mas se divergi quando Marcuschi e Xavier (2010) afirmam que o uso virtual da língua em gêneros digitais é concernente à prática social da escrita. Isso desconsidera a característica híbrida do uso virtual da linguagem que determina as possibilidades de comunicação por meio do texto verbal, não verbal, sonoro ou híbrido. A variação está no texto verbal em gêneros digitais. É o usuário da língua que define e escolhe como quer organizar e construir o seu "querer de dizer" (TEDESCO, 2013), utilizando os recursos linguísticos necessários para tal propósito.

Além deste aspecto, o uso virtual da linguagem não se desenvolve de maneira linear e sequencial como em outros gêneros discursivos, vinculados ao uso da escrita como, por exemplo, os textos clássicos. Este é um uso que se desenvolve em ambiente hipertextual, o que implica ser multilinearizado, multisequencial e indeterminado (MARCUSCHI, 1999). Consequentemente, tais aspectos circunscritos ao hipertexto são significativos para compreendermos o comportamento do interactante em gêneros digitais, os quais de maneira simultânea exercem as atividades de leitor e de produtor de textos na Internet.

O processo de leitura no contexto da Internet como, por exemplo, na rede social Facebook, reflete a importância do acionamento do conhecimento prévio na atividade de depreensão e (re)construção de sentidos. O conhecimento prévio ou de mundo é um dos três principais conhecimentos que organiza o sistema cognitivo. Os demais são o conhecimento linguístico e o conhecimento sociointeracionista $(\mathrm{KOCH}, 2002)$, os quais também estão envolvidos no processo de compreensão. Dijk (2012, p. 87) observa que "os usuários da língua não estão apenas envolvidos em processar o discurso; ao mesmo tempo, eles também estão engajados em construir dinamicamente sua análise e interpretação subjetiva on-line" (DIJK, 2012, p. 87).

Logo, na Internet, o interactante está exposto a uma multiplicidade de informações em que precisa, na atividade de interpretação das informações, acionar o sistema cognitivo e o contexto social, para produzir textos verbais coesos e coerentes. Nesta lógica, encontram-se as expressões anafóricas diretas e suas funções discursivas (TEDESCO, 2002), como elementos coesivos, e as relações de intertextualidade, como fator de coerência textual, as quais serão consideradas nas seções subsequentes.

\section{As relações intertextuais no gênero digital comentário no Facebook}

O fenômeno da intertextualidade é considerado uma característica muito relevante de hipertextos, conforme observa Koch (2014), ao dizer que o hipertexto se define como um "um texto múltiplo" ( $\mathrm{KOCH}, 2014$, p. 225) e por conta desta qualidade textos se fundem e dialogam entre si de modo que, na Internet, são acessados a partir do click do mouse, organizando uma cadeia de informações.

Publicações recorrentes a respeito do fenômeno de coerência em ambiente de 
hipermídia costumam discutir, teoricamente, os conceitos de hipertexto, da própria intertextualidade, de interatividade e de hipermídia, embora não se aprofunde, analiticamente, na forma como a propriedade de coerência ocorre em ambientes interativos como, por exemplo, as redes sociais. Isto revela uma imprecisão nas investigações de aspectos de textualidade no hipertexto, no contexto da Internet.

Analisar o processo de intertextualidade num ambiente interativo e hipertextual como a rede social Facebook não é simples, por causa da complexidade do suporte de gêneros digitais, como é o caso do gênero comentário. A complexidade do suporte Facebook não se reflete na dinâmica da interação, que é simples, mas na compreensão que todas informações presentes no suporte estão conectadas entre si, porém, numa relação não linear. Neste sentido, Marcuschi (2001, p. 83) pontuou que "o escritor de um hipertexto produz uma série de previsões para ligações possíveis entre segmentos, que se tornam opções de escolha para hipernavegadores". Estas ligações possíveis entre textos determina a intertextualidade em ambientes interativos como a rede social Facebook.

O suporte Facebook apresenta a circulação de gêneros discursivos digitais diversificados como os comentários, o Bate-papo, as mensagens, o feed de notícias, a linha do tempo, o álbum de fotos, entre outros gêneros discursivos digitais. Aliás, 0 conceito 'digital' explicita a natureza discursiva desses gêneros, pois, de acordo com Marcuschi (2008, p. 155), não "não abrange um gênero particular, mas dá origem a vários deles...".

Entre os gêneros digitais que circulam no suporte Facebook se sobressai o gênero digital comentário, o qual é utilizado pelos interactantes para expressarem opiniões ou para manifestarem, subjetivamente, suas emoções a partir do uso de texto verbal, não verbal, sonoro ou de estilo híbrido.

A razão que motiva a publicação de textos em comentários, no Facebook, é a publicação de outros textos no perfil, sendo este privado ou público. Logo, o gênero discursivo comentário tem a função discursiva de ser uma contrapartida a textos publicados em perfis, no suporte Facebook. Nesse sentido, a percepção de Genette (2010) a respeito das relações de intertextualidade permite o entendimento do processo discursivo que ocorre entre o gênero digital comentário e os textos publicados em perfis sociais.

Genette (2010) trouxe importante contribuição aos estudos de intertextualidade, quando fala sobre o conceito de transtextualidade, isto é, todo texto seria uma transcendência textual de outro texto. Assim, os textos em comentários publicados no Facebook são uma transcedência textual de textos publicados em perfis sociais.

Para Genette (2010), o fenômeno da transtextualidade apresentaria cinco tipos de relações transtextuais. O primeiro tipo e mais conhecido é a intertextualidade, que se define pela relação entre textos que se realisa discursivamente a partir das categorias: referência, citação e alusão. A referência e a citação são categorias concernentes à intertextualidade explícita, e a alusão é concernente à intertextualidade implícita conforme propõem Koch, Bentes e Cavalcante (2012).

O segundo tipo de relação de transtextualidade proposta por Genette (2010) é o paratexto, o qual se define como títulos, subtítulos, notas, epígrafes e capas. O terceiro tipo de relação transtextual é a arquitextualidade, que se caracteriza por uma menção silenciosa, segundo o autor, a outros textos. Por último, o quinto tipo de transtextualidade é a metatextualidade, que apresenta a característica de ser um comentário, de acordo 
com o autor, que une um texto a outro texto.

Especificamente é a transtextualidade com base na metatextualidade que permite compreender a ligação estabelecida entre sequências textuais de comentários com outros textos publicados em perfis sociais. A metatextualidade estabelece que o gênero digital comentário é uma superestrutura discursiva, porque a estrutura textual do gênero digital designa uma contrapartida para um texto matriz. Por isso, aqui, se propõe que os comentários, juntamente, com os textos-fonte, publicados em perfis sociais, formam um par metatextual. Exatamente pelo uso do gênero digital como contrapartida de textosfonte, conforme se ilustra com a figura proposta por este estudo:
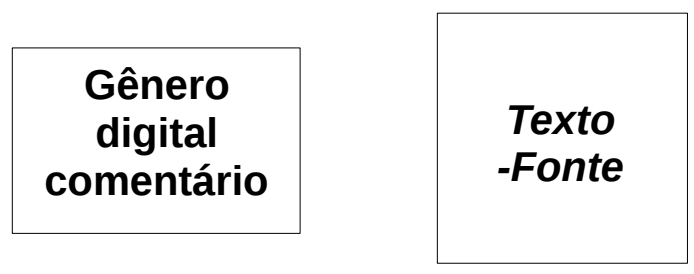

Figura 1: Par metatextual. Fonte: próprios autores.

A estrutura textual dos comentários - verbal, não verbal ou sonora - está unida ou coadunada a outro texto - qualquer que seja este -, o qual tenha sido publicado em perfis do Facebook. Sendo estes pessoal ou público. Além disto, como o artigo está tratando de um gênero hipertextual, o próprio comentário pode tornar-se texto-fonte para outros comentários desenvolvidos num perfil qualquer, aspecto que reflete a interatividade de modo coletivo.

Koch, Bentes e Cavalcante (2012) observam ainda que a metatextualidade estabelece uma relação intertextual temática, pois, está pressuposto que o comentário produzido mantém a progressão do tema desenvolvido no texto-fonte, conforme pode ser verificado no exemplo a seguir, em que o comentário do interactante se refere ao artigo da jornalista Cantanhêde sobre as eleições americanas, em que os principais candidatos eram Hillary Clinton, do partido americano Democrata, e Donald Trump, do partido americano Republicano, no ano de 2016:

\section{mundo virando para a extrema direita. Putin deve estar com risos ironicos disfarçados. \\ Figura 2: comentário sobre a eleição americana. \\ Fonte: publicado no Facebook, da jornalista Cantanhêde. Acesso em: https://www.facebook.com/elianecantanhedejornalista/posts/527186494153400}

O interactante mantém a progressão temática em seu comentário ao fazer uma alusão à informação 'extrema direita', que determina a base ideológica do partido Republicano do então candidato Donald Trump. Observa-se que a alusão é uma das particularidades da intertextulidade, em que o uso da informação 'extrema direita' estabelece relação contextual (FIORIN, 1994) com a discussão proposta no artigo da jornalista Cantanhêde. Assim, o exemplo do comentário confirma a relação metatextual com o artigo da jornalista, publicado no perfil da mesma no Facebook, e organiza um par 
metatextual.

A intertextualidade temática e também a explícita e implícita, no gênero comentário, são assinaladas no nível microdiscursivo com as funções discursivas de expressões anafóricas direta (TEDESCO, 2002), a partir da manutenção de referentes textuais, da retomada de referentes, da recategorização avaliativa de referentes textuais e da recategorização de referentes textuais, durante a progressão de referente no texto. Aspectos que serão tratados na próxima seção.

\section{As funções discursivas de expressões anafóricas e implicações intertextuais}

Na seção anterior, foi abordado a respeito da intertextualidade, importante fator de coerência textual, no gênero discursivo comentário, que é de natureza digital. A função discursiva do gênero digital é proporcionar o entretenimento aos internautas, textualmente. Nesse sentido, vamos observar como as expressões anafóricas diretas indicam as relações intertextuais presentes no gênero hipertextual e digital.

As expressões anafóricas são elementos coesivos relacionados com o processo discursivo da referenciação, que, segundo Mondada \& Dubois (2003) parte do princípio da instabilidade das entidades da língua, conforme a relação do linguístico com o cognitivo. Por isso, na perspectiva da referenciação (MONDADA \& DUBOIS, 2003), não há estabilidade das coisas no mundo e na língua. O que há é uma instabilidade dos objetos, discursivamente. Essa percepção é essencial para se entender a importância linguística e discursiva de formas linguísticas de coesão referencial.

A coesão referencial, com as estratégias textuais anafóricas e catafóricas $(\mathrm{KOCH}$, 1999), permite que se estabeleça a progressão do texto, de forma a costurar o texto sintática e semanticamente. Especificamente, a coesão por meio de expressões definidas anafóricas faz o encadeamento discursivo de referentes, objetos do discurso, na superfície textual. O encadeamento discursivo do referente textual, na superfície do texto, segundo Koch (2002), é construída pelo encadeamento de referentes textuais por meio de operações discursivas: a ativação, a reativação e a de-ativação.

Sobre a ativação, Koch (2002) diz que, durante a produção do texto, referentes discursivos são ativados, acionados, de modo a preencherem um "endereço cognitivo", segundo a autora, e, assim, os referentes ativados ficam disponíveis - online ${ }^{1}$ - para serem reativados em outro momento necessário da produção textual.

Neste sentido Tedesco (2002), ao analisar textos argumentativos produzidos por estudantes, ampliou o sentido da operação discursiva de ativação de referentes ao analisar cadeias anafóricas diretas. A respeito da estratégia de ativação de referente textual, Tedesco (2002) explica que os referentes textuais, quando ativados nas cadeias anafóricas diretas, adquirem a função discursiva de introdutores, pois, uma vez introduzidos os referentes, estes são podem ser reativados no momento necessário do desenvolvimento do texto, como, por exemplo, a figura do texto verbal do comentário, a seguir, que ilustra uma contrapartida para o artigo da jornalista Cantanhêde, "Análise: com uma carta para Hillary e outra para Trump", publicado em seu perfil no Facebook, no ando de 2016:

\section{Conceito em inglês que significa conectado.}




\section{Trump foi demonizado o tempo todo, \\ porém alguma coisa no sistema, cansou os americanos, que embarcaram pra valer no discurso nada convencional de Donald. Um pouco de medo e perplexidade paira sobre uma parte do mundo e para alguns porque não? Um pouco de esperança, que o digam os milhões de americanos que votaram em Trump, apesar de Trump. Bom dia Eliane, Bom Dia internautas}

Figura 3: comentário sobre a eleição americana.

Fonte: https://www.facebook.com/elianecantanhedejornalista/posts/527186494153400

No comentário, apresentado pela Figura 2, pode ser observado, no início do texto, a ativação do referente textual 'Trump' que, segundo a reflexão de Tedesco (2002), apresenta a função discursiva de introdução. Pois, é a primeira menção do referente na superfície textual. O qual será reativado $(\mathrm{KOCH}, 2002)$ em outro momento do texto. A estratégia de reativação é ampliada por Tedesco (2002) com as funções discursivas de manutenção de núcleo de referente, de retomada, de recategoriza e de recategorização avaliativa. No caso do texto do comentário, o referente 'Trump' é reativado pela função de retomada, conforme a cadeia anafórica:

\section{O Trump $\rightarrow$ Donald $\rightarrow$ Trump $\rightarrow$ Trump}

O referente textual 'Trump' se desenvolve no texto do comentário de modo a explicitar o propósito comunicativo e a situação comunicativa do texto verbal. Com a cadeia anafórica é possível compreender que a estratégia textual de reativação de referentes discursivos, segundo Koch (2002), é um processo que um referente discursivo, novamente, é acessado, conectado, para possibilitar a produção de sentidos. A estratégia discursiva de reativação e as consequentes funções discursivas que os elementos linguísticos desempenham na cadeia anafórica direta confirmam a relação metatextual que se constrói nos textos verbais dos comentários com os textos-fonte.

Para exemplificar como as funções discursivas refletem as relações intertextuais no gênero digital comentário, será apresentado um trecho de outro artigo de opinião da jornalista Eliane Catanhêde - "Governo usa aids contra a maioridade penal" - e comentários de interactantes sobre o artigo. Na época da publicação do artigo na rede social Facebook, o país discutia a necessidade da redução da maioridade penal para 16 anos. A proposta de redução penal foi motivada pelo crescente número de crimes cometidos por jovens de 16 anos de idade. Crimes como assassinatos, por exemplo. Tal temática não é apenas uma reflexão jurídica, mas também é uma reflexão política e social. A seguir, um trecho do artigo da jornalista:

Exemplo 1: Artigo de Cantanhêde e referentes discursivos

"A taxa de contaminação por aids no sistema prisional brasileiro é $60 \%$ superior à taxa na população total do País. São 1.215 contaminados a cada cem mil presidiários, contra 20,2 por cem mil fora das prisões.

2 O artigo e os comentários sobre o mesmo foram retirados de: https://www.facebook.com/pg/elianecantanhedejornalista/posts/?ref=page internal 
Os dados fazem parte de um detalhado estudo que será divulgado oficialmente nesta segunda-feira, 22, pelo ministro da Justiça, José Eduardo Cardozo, em sua cruzada contra os projetos em tramitação no Congresso para a redução da idade penal de 18 para 16 anos".

Pontua-se que, no presente artigo, não serão tratadas todas as cadeias anafóricas de referentes textuais que foram ativados e introduzidos no artigo "Governo usa aids contra a maioridade penal". Aqui, serão consideradas cadeias anafóricas dos referentes textuais que 'sistema prisional brasileiro', 'Ministro da Justiça' e 'a redução da idade penal de 18 anos para 16 anos', as quais permitirão o leitor compreender como as expressões anafóricas diretas refletem as relações intertextuais.

No trecho destacado do artigo, observa-se a função discursiva introdução de referentes textuais conforme os objetos discursivos: 'sistema prisional brasileiro', 'Ministro da Justiça' e 'a redução da idade penal de 18 anos para 16 anos'. A introdução desses referentes no texto leva o leitor ou o interlocutor ao acionamento do conhecimento de mundo, para a atividade de depreensão dos sentidos. Por isso, Dijk (2012, p. 87) observa que "os usuários da língua não estão apenas envolvidos em processar o discurso; ao mesmo tempo, eles também estão engajados em construir dinamicamente sua análise e interpretação subjetiva on-line". Logo, a introdução do referente discursivo 'sistema prisional brasileiro' guia o leitor a mobilizar tudo que ele sabe a respeito do referente discursivo, para, simultaneamente, analisar e interpretar a informação. Por esse motivo, o processo de depreensão dos sentidos é uma operação construída na relação do explícito, a partir das estruturas linguísticas, com o implícito, conforme o conhecimento de mundo e as relações de intertextualidade, por exemplo. Nesse sentido, apresenta-se, no exemplo 2, a cadeia anafórica do referente 'sistema prisional brasileiro' com o momento da sua ativação e introdução, no primeiro parágrafo do artigo de Cantanhêde, até a sua última reativação por recategorização, no oitavo parágrafo:

\section{Exemplo 2: Cadeia anafórica do referente 'sistema prisional brasileiro'}

Sistema prisional brasileiro (Introdutor - $1^{\circ}$ parágrafo) $\leftrightarrow$ cem mil presidiários (10 parágrafo) $\leftrightarrow$ prisões ( $1^{\circ}$ parágrafo) $\leftrightarrow$ sistema carcerário ( $3^{\circ}$ parágrafo) $\leftrightarrow$ o sistema (5० parágrafo) $\leftrightarrow$ o sistema ( $5^{\circ}$ parágrafo) $\leftrightarrow$ esse sistema (50 parágrafo) $\leftrightarrow$ sistema prisional (60 parágrafo) $\leftrightarrow$ presídios (6 $6^{\circ}$ parágrafo) $\leftrightarrow$ grandes presídios (8o parágrafo) $\leftrightarrow$ penitenciárias ( $8^{\circ}$ parágrafo).

$\mathrm{Na}$ cadeia anafórica direta de 'sistema prisional brasileiro', nota-se, primeiro o processo de ativação por introdução, conforme pontuado. Em seguida, há a operação de reativações do referente discursivos com as funções discursivas:

a) manutenção do nome/núcleo 'sistema' nos sintagmas nominais: 'o sistema', 'esse sistema' e 'sistema prisional';

b) recategorização com o uso do sinônimo da palavra adjetiva prisional no sintagma nominal 'sistema carcereiro';

c) recategorização do referente nos sintagmas 'cem mil presidiários', 'prisões', 'presídios', 'penitenciárias';

d) recategorização avaliativa do referente com o uso do sintagma nominal 'grandes presídios', a partir do uso do adjetivo 'grandes', anteposto ao nome 'presídios'.

Assim, no processo de progressão do referente textual 'sistema prisional 
brasileiro', percebe-se que as funções discursivas das expressões anafóricas diretas organizam o projeto de dizer da jornalista Cantanhêde e dão destaque para os problemas que envolvem o sistema prisional no Brasil, que é um dos fatores que dificulta legalizar a redução da maioridade penal.

A cadeia do referente textual 'Ministro da Justiça' também demonstra a sua progressão no projeto de dizer da jornalista Cantanhêde, segundo as funções discursivas desempenhadas pelo referente no discurso:

\section{Exemplo 3: Cadeia anafórica do referente 'Ministro da Justiça'}

Ministro da Justiça (Introdutor $-2^{\circ}$ parágrafo) $\leftrightarrow$ José Eduardo Cardozo (2० parágrafo) $\leftrightarrow$ em sua cruzada ( $2^{\circ}$ parágrafo) $\leftrightarrow$ o ministro ( $3^{\circ}$ parágrafo) $\leftrightarrow$ Cardozo (4०

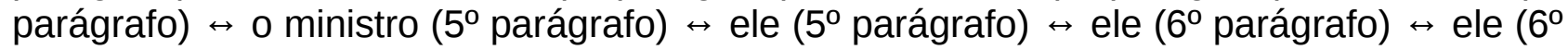
parágrafo) $\leftrightarrow$ José Eduardo Cardozo (70 parágrafo) $\leftrightarrow$ ele ( $8^{\circ}$ parágrafo) $\leftrightarrow$ segundo ele

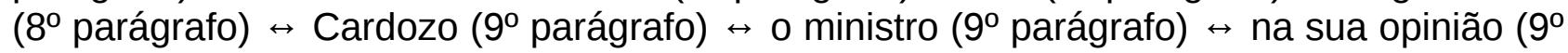
parágrafo) $\leftrightarrow$ o ministro ( $10^{\circ}$ parágrafo).

$\mathrm{Na}$ cadeia anafórica, verifica-se que o referente é ativado, pela função discursiva de introdução, no segundo parágrafo do artigo, e, no mesmo parágrafo, já é reativado pela função discursiva de recategorização, no uso do nome 'José Eduardo Cardozo'. No exemplo 1, pode ser observado que o recategorizador 'José Eduardo Cardozo' apresenta, sintaticamente, a atribuição de aposto, que é um substantivo que altera, semanticamente, um núcleo nominal (BECHARA, 2001). Essa complementação semântica, no texto, orienta o leitor para quem está no cargo de Ministro da Justiça e que apresenta a incumbência de representar o governo em discussões vinculadas ao contexto jurídico. $\mathrm{O}$ referente textual ainda é reativado por:

a) recategorizações conforme 'em sua cruzada', 'segundo ele', 'em sua opinião', as quais demonstram a alteração da estrutura linguística do referente textual, sem comprometimento do sentido;

b) manutenção do núcleo do referente 'Ministro da Justiça' com o uso de 'o ministro';

c) manutenção do sobrenome 'Cardozo' do recategorizador 'José Eduardo Cardozo';

d) retomada do referente com o uso do pronome de terceira pessoa do singular 'ele.

Para completar a análise dos referentes textuais, apresenta-se a terceira cadeia anafórica do referente textual 'a redução da maioridade penal de 18 anos para 16 anos', de acordo com o exemplo 4:

Exemplo 4: Cadeia anafórica do referente 'A redução da idade penal'

A redução da idade penal de 18 para 16 anos (Introdutor - $2^{\circ}$ parágrafo) $\leftrightarrow$ eventual redução da maioridade penal (40 parágrafo) $\leftrightarrow$ a redução (50 parágrafo) $\leftrightarrow$ a

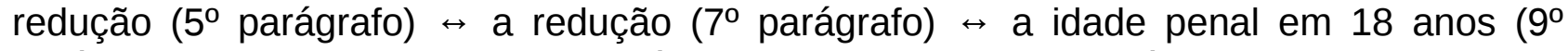
parágrafo) $\leftrightarrow$ a idade penal (90 parágrafo) $\leftrightarrow$ questão (110 parágrafo) $\leftrightarrow$ a maioridade ( $11^{\circ}$ parágrafo).

Como a cadeia do referente textual 'a redução da maioridade penal de 18 para 16 anos' demonstra, a sua primeira ativação ocorre no segundo parágrafo do texto e o mesmo é reativado apenas no quarto parágrafo. Em vista disso, Koch (2002) diz que a operação de reativação tem importância, exatamente, por manter o referente textual em foco na memória de curto termo. Isso implica na estabilização do processo textual e na 
progressão dos referentes, segundo a autora. No caso do referente 'redução da maioridade penal', a sua progressão é sinalizada pelas funções discursivas:

a) recategorização no uso dos sintagmas 'eventual redução da maioridade penal' e 'questão';

b) a manutenção do nome 'redução' no sintagma nominal 'a redução';

c) manutenção do complemento nominal em 'a idade penal de 18 anos' e em 'a idade penal';

d) a manutenção do complemento nominal 'maioridade penal' do recategorizador 'eventual redução da maioridade penal';

e) manutenção do termo 'maioridade' do complemento nominal 'da maioridade penal'. São estas funções discursivas explicitadas na progressão dos referentes textuais que indicam as relações de intertextualidade no gênero comentário. Para relembrar, os comentários publicados em perfis do Facebook estabelecem uma relação metatextual com textos que lhes servem de fontes, o que implica na intertextualidade temática nos textos verbais que estruturam os comentários produzidos por interactantes no Facebook.

No entanto, a intertextualidade temática não é estabelecida apenas pela relação metatextual, mas também por outros perfis de relações intertextuais, explícitas e implícitas. A intertextualidade explícita é reconhecida em sequências textuais com função de citação e com função de referência (KOCH, BENTES \& CAVALCANTE, 2012). Quanto à intertextualidade implícita é refletida em sequências textuais que fazem alusão ao contexto de informações. Sendo assim, observe os comentários, nos exemplos 5, 6, 7, 8, 9, que foram publicados por interactantes do perfil da jornalista Cantanhêde, a respeito dos referentes textuais, os quais foram analisados nas cadeias anafóricas dos exemplos ${ }^{3}$ 2, 3 e 4:

Exemplo 5: Perfeito!! A lei é para coibir os crimes e não para fomentá-los!!!

Exemplo 6: A vida na prisão é dura. Claro, se fosse boa, quem deixaria de roubar, traficar drogas, estuprar ou matar com medo de ir para cadeia?

Exemplo 7: Estão fazendo de tudo para não reduzir, inclusive assumirem as péssimas condições do sistema prisional como desculpa. Agora, reformar o sistema prisional, nem brincado.

Exemplo 8: Esse ministro da justiça lembra o Delfim Neto quando ministro da agricultura. Só fala besteira... Lembram: "As batatas têm que batatear, não vejo outra saída...".

Exemplo 9: Está evidente que um jovem que entrar no sistema carcerário terá uma propensão muitíssimo maior de sair de lá com aids. Se é que vai conseguir sair vivo de lá, disse o ministro à reportagem. Esse ministrinho, só fala besteira, e as vítimas mortas por esses bandidos? E as famílias dessas vítimas? Eles não contam. Ridículo esse senhor.

3 É importante observar que os comentários dos exemplos 5, 6, 7, 8 e 9 são apresentados Ipsis litteris ao exposto no perfil da jornalista Cantanhêde, retirados de: https://www.facebook.com/pg/elianecantanhedejornalista/posts/?ref=page internal 
Inicia-se a análise com o comentário do exemplo 5 , em que o referente textual 'a redução da maioridade penal de 18 anos para 16 anos' é reativado por recategorização com o sintagma nominal 'a lei'. Essa forma recategorizada confirma, portanto, a existência de intertextualidade temática do comentário com o texto-fonte. A intertextualidade temática está subentendida pela intertextualidade implícita por alusão.

Desta forma, o uso do recategorizador 'a lei', com a modificação completa do núcleo do referente textual 'redução da maioridade penal', indica a assimilação do tema tratado no texto-fonte que serve de contexto para a compreensão do projeto de dizer exposto no comentário do exemplo 5. Isso solicita do interactante o acionamento do contexto sociocognitivo para depreender sentidos do artigo, para, em seguida, apresentar a sua contrapartida, utilizando o recategorizador 'a lei'. Logo, a função discursiva de recategorização, quando modifica totalmente a estrutura sintagmática do referente textual, determina a relação intertextual implícita, em que a sequência textual do comentário faz uma alusão ao texto-fonte, neste caso, o artigo "Governo usa aids contra a redução da maioridade penal".

A sequência textual do comentário, que compõe o exemplo 6, traz a manutenção do recategorizador 'prisão', que é um caso de variação gramatical do adjetivo prisional que estrutura o referente discursivo 'sistema prisional brasileiro'. Diferentemente do recategorizador 'a lei', a manutenção do recategorizador 'prisão' indica a intertextualidade explícita com o texto-fonte. Ao produzir o comentário, o interactante seleciona a informação da cadeia anafórica do referente textual 'sistema prisional brasileiro' para apresentar o seu propósito comunicativo. A manutenção do recategorizador 'prisão' é uma forma de intertextualidade explícita por citação.

No comentário do exemplo 7, verifica-se a reativação dos referentes textuais 'a redução da maioridade penal' e 'sistema prisional brasileiro'. No caso da reativação do referente textual 'a redução da maioridade penal', a mesma é operada pelo recategorizador 'reduzir', forma infinitiva derivada do nome 'redução' que estrutura o referente discursivo. Como a recategorização mantém a base ou o radical da palavra redução, contata-se a intertextualidade explícita por citação da forma recategorizada com o referente textual do texto-fonte. A intertextualidade explícita por citação ainda se manifesta na recategorização avaliativa em 'as péssimas condições do sistema prisional' e na manutenção de 'sistema prisional'. O aspecto diferencial é que o recategorizador avaliativo apresenta de maneira evidente a opinião do interactante, a partir da utilização do adjetivo 'péssimas', que orienta para um ponto de vista crítico do produtor do texto. No exemplo 7, prevalece à relação intertextual explícita por citação

A sequência textual do comentário do exemplo 8 é constituída pelo recategorizador 'esse ministro da justiça'. O pronome demonstrativo, no recategorizador, apresenta um valor dêitico, porque localiza no contexto discursivo o referente textual, além de apresentar um teor irônico que explicita uma contrariedade na opinião em relação ao Ministro da Justiça. Apothéloz e Chanet (2003) postulam que o uso do demonstrativo em expressões anafóricas como 'esse ministro da justiça', em início de parágrafo dá maior visibilidade para os objetos discursivos, como pode ser verificado no texto do exemplo 8, em que o recategorizador expõe a opinião do interactante.

É interessante sinalizar que o recategorizador 'esse ministro da justiça' não modificou a estrutura sintagmática do referente textual, mas a inserção do pronome demonstrativo 'esse' modificou semanticamente o referente, conforme o traço de ironia inerente no pronome demonstrativo. Por causa da não modificação estrutural do referente 
textual, constata-se que o recategorizador 'esse ministro da justiça' estabelece a intertextualidade explícita, por citação.

A estrutura textual do comentário do exemplo 9 apresenta uma complexidade intertextual bem interessante. As expressões anafóricas 'sistema carcerário', 'esse ministrinho' e 'o ministro' são reativações dos objetos discursivos 'sistema prisional brasileiro' e 'ministro da justiça'. Em 'sistema carcerário', é constatado que o recategorizador mantém o núcleo do referente textual - sistema - vinculado com o sinônimo 'carcerário'. Isto implica na relação intertextual explícita por citação. A relação intertextual por citação ainda é verificada nas reativações do objeto discursivo 'Ministro da Justiça', com a recategorização avaliativa 'esse ministrinho' e a manutenção do núcleo do referente em 'o ministro'.

No recategorizador avaliativo 'esse ministrinho', o pronome demonstrativo localiza o referente textual no contexto e realça a ironia e o valor depreciativo do sufixo diminutivo '-inho', o qual explicita o ponto de vista crítico e subjetivo do produtor do texto. O núcleo do recategorizador 'ministrinho' é uma palavra derivada por sufixação. A relação intertextual por citação está mantida no radical do vocábulo recategorizador. A manutenção do referente textual 'o ministro' é outra expressão anafórica direta que reflete a intertextualidade explícita por citação.

No mesmo exemplo 8, a estrutura textual do comentário apresenta o recategorizador avaliativo 'ridículo esse senhor' que reativa o referente textual Ministro da Justiça. Há no recategorizador avaliativo uma mudança completa da estrutura linguística da forma discursiva introdutória 'Ministro da Justiça'. Na verdade, é uma estrutura que destoa da estrutura lógica do sintagma nominal, que seria constituído de pronome demonstrativo + adjetivo + substantivo ou formado por pronome demonstrativo + substantivo + adjetivo.

$\mathrm{Na}$ forma recategorizadora avaliativa 'ridículo esse senhor', o adjetivo 'ridículo' tem uma função sintática vocativa que estaria explícita se tivesse sido utilizada a vírgula antes do sintagma 'esse senhor'. Conforme a percepção sociolinguística, o que temos com este recategorizador avaliativo é uma variação de ordem sintática, definida pela ausência da vírgula. É um aspecto que reflete uma particularidade do uso da língua em gênero digital. Com a forma recategorizadora avaliativa se compõe uma cadeia anafórica:

\section{O ministro $\rightarrow$ Esse ministrinho $\rightarrow$ Ridículo esse senhor.}

Além disso, a forma recategorizadora avaliativa orienta para uma alusão do intertexto. A intertextualidade explícita por citação, igualmente, está expressa na retomada do referente textual 'um jovem', o qual é ativado na progressão do artigo da jornalista Cantanhêde. Este referente é um exemplo da operação cognitiva 'de-ativação", proposta por Koch (2002, p. 83), em que "desloca-se a atenção para um outro referente textual e desativando-se, assim, o referente que estava em foco anteriormente". É a introdução de um novo referente textual que mantém uma relação semântica com o objeto discursivo 'redução da maioridade penal de 18 para 16 anos'. No artigo 'Governo usa aids contra a maioridade penal', o objeto discursivo 'um jovem' apresenta uma progressão referencial, conforme a cadeia anafórica do exemplo 10:

Exemplo 10: cadeia anafórica do referente 'um jovem' 
Um jovem (Introdutor $-3^{\circ}$ parágrafo) $\leftrightarrow 40$ mil jovens (50 parágrafo) $\leftrightarrow$ jovens ( $7^{\circ}$ parágrafo) $\leftrightarrow$ jovens ( $8^{\circ}$ parágrafo) $\leftrightarrow$ a "molecada" (80 parágrafo) $\leftrightarrow$ gado arrebanhado (8 $8^{\circ}$ parágrafo) $\leftrightarrow$ o jovem ( $8^{\circ}$ parágrafo) $\leftrightarrow$ aviãozinho ( $8^{\circ}$ parágrafo) $\leftrightarrow$ diploma de traficante ( $8^{\circ}$ parágrafo) $\leftrightarrow$ o jovem $\left(10^{\circ}\right.$ parágrafo $) \leftrightarrow$ adulto (10 parágrafo).

Logo, no texto verbal do exemplo 9, a retomada do referente 'um jovem' organiza uma pequena cadeia anafórica com o uso da forma recategorizadora avaliativa 'esses bandidos' que torna mais compreensível o propósito comunicativo do comentário.

O comentário do exemplo 9 apresenta a relação intertextual explícita por citação e a intertextualidade implícita por alusão, que define uma intertextualidade híbrida fundamentada nas funções discursivas de formas anafóricas diretas. Perfil de intertextualidade particular do gênero hipertextual e digital comentário.

Portanto, alguns casos de relações de intertextualidade discutidas com os exemplos propostos no presente estudo, são compreendidos a partir das funções discursivas de expressões anafóricas diretas, as quais nos permitem apresentar outras observações:

a. O gênero discursivo digital comentário é uma superestrutura discursiva, em que o comentário estabelece relação metatextual com um texto que the serve de fonte. $\mathrm{O}$ que determina a existência de um par metatextual.

b. A estrutura linguística do gênero comentário é constituída por texto verbal, não verbal, sonoro e híbrido.

c. Há no par metatextual uma intertextualidade temática concretizada pela relação do microdiscursivo - com as funções discursivas de expressões anafóricas diretas (TEDESCO, 2002) - com o macrodiscursivo - conforme as relações de intertextualidade explícita e implícita.

d. As expressões anafóricas diretas, que retomam ou fazem manutenção de núcleo de referentes textuais do texto-fonte ou reativam referentes textuais, assinalam para intertextualidade explícita por citação, de forma a estabelecer a manutenção do ponto de vista do produtor do texto-fonte.

e. É necessário destacar que estudo sobre a estrutura discursiva do gênero comentário confirma a existência de intertextualidade explícita por referência, quando nos comentários dos interactantes, por exemplo, no perfil público da jornalista Cantanhêde, é reativado por retomada o referente Eliane Cantanhêde: "Eliane sempre brilhante!!!".

f. As funções discursivas anafóricas também indicam a intertextualidade explícita composta por citação e por referência em textos verbais de comentários publicados no Facebook. Bem como observado nos comentários publicados perfil publico da jornalista Cantanhêde, em que os textos apresentavam formas anafóricas ou retomando ou fazendo manutenção de núcleos de referentes textuais do textofonte, juntamente com a reativação da referente textual Cantanhêde. Por exemplo: "Eliane Cantanhêde, Rodrigo Maia é um deserto de caráter". Rodrigo Maia é um dos referentes textuais do artigo "Não tem governo".

g. As recategorizações avaliativas de referentes textuais nos comentários orientam para a relação intertextual implícita. Neste caso, observa-se que a alusão no ponto de vista da sequência textual no comentário expressa um julgamento subjetivo a respeito de referentes do texto-fonte, um julgamento pessoal, sem consistência 
argumentativa: "Estou impressionada com os argumentos usados para justificar que bandidos continuem soltos".

É a compreensão dessa híbrida, hipertextual e intertextual superestrutura discursiva do gênero digital comentário que podemos compreender a heterogeneidade discursiva $(\mathrm{KOCH}, 2002)$ da linguagem na Internet. Não é à toa que o seu potencial está na descentralização da informação e no entretenimento das mesmas.

\section{Considerações finais}

O presente artigo teve a pretensão de apresentar estudo recente sobre a materialidade linguística e discursiva do gênero discursivo digital comentário, o qual foi desenvolvido em recente pesquisa. O fim foi elucidar como o fenômeno de intertextualidade ocorre em gênero hipertextual e digital colabora para o entendimento de como se desenvolve o processo de interação pela linguagem em redes sociais, em que o interactante acumula as funções de leitor e produtor de texto, simultaneamente.

O que se espera é que este trabalho estimule outros estudos sobre o uso virtual da linguagem, reconhecendo nesta o potencial de terceira modalidade da língua, conforme os pressupostos de Tedesco (2013), e estudos de linguagem constituídos por percepções críticas que não tratem o uso virtual da linguagem como algo espetacular, que substitui os demais usos da língua, ou como algo a ser desconsiderado, por não corresponder ao prescritivismo linguístico.

O uso virtual da linguagem fundou a comunicação coletiva e interativa e é deste modo que deve ser pesquisada, como produto de uma comunicação digital. Assim, poderemos tornar os usuários mais jovens críticos diante dessa comunicação digital, pois, estarão cientes que desempenham neste espaço uma leitura não linear, intertextual, fragmentada, a qual demanda do apoio do sistema cognitivo e do contexto social, para depreender sentidos de forma coerente.

\section{Referências}

APOTHÉLOZ, D. \& CHANET, C. Definido e demonstrativo nas nomeações. In.: CAVALCANTE, M. M; RODRIGUES, B. B.; CIULLA, A. (org.). Referenciação. São Paulo: Contexto, 2003. p. 131-176.

BECHARA, Evanildo. Moderna gramática portuguesa. 37.ed. rev. e ampl. Rio de Janeiro: Lucerna: 2001.

CASTELLS, M. A Sociedade em rede. A era da informação: economia, sociedade e cultura. V. 1. São Paulo: Paz e Terra, 1999.

DIJK, T. A. Van. Discurso e contexto: uma abordagem sociocognitiva. Tradutor Rodolfo Ilari. São Paulo. Contexto. 2012.

5 Exemplo de comentário retirado de: https://www.facebook.com/pg/elianecantanhedejornalista/posts/? ref=page_internal 
FIORIN, J. L. Polifonia Textual e Discursiva. In.: BARROS, D. L. P. de; FIORIN, J. L. (org.). Dialogismo, Polifonia, Intertextualidade. Editora da Universidade de São Paulo, 1994. p. 29-36.

GENETTE, G. Palimpsestos: a literatura de segunda mão. Tradução: Cibele Braga et al. Edições Viva a Voz. Belo Horizonte, 2010.

KOCH, I. G. V. A coesão textual. 11. ed. São Paulo: Contexto, 1999.

KOCH, I. G. V. Desvendando os segredos do texto. São Paulo: Cortez, 2002.

KOCH, I. G. V. As tramas do texto. 2.ed. São Paulo: Contexto, 2014.

$\mathrm{KOCH}$, I. G. V; BENTES, A. C.; CAVALCANTE, M. M. Intertextualidade: diálogos possíveis. $3^{\mathrm{a}}$.ed. São Paulo: Cortez, 2012.

LÉVY, P. Cibercultura. São Paulo: Editora 34, 2010. 3a edição.

MARCUSCHI, L. A. Linearização, cognição e referência: o desafiodo hipertexto. Comunicação apresentada no IV Colóquio da AssociaçãoLatinoamericana de Analistas do Discurso. Santiago, Chile, 5 a 9 de abril de 1999. Disponível em: http://web.uchile.cl/facultades/filosofia/Editorial/libros/discurso_cambio/17Marcus.pdf.

Acesso em: 01 fez. 2019.

MARCUSCHI, L. A. O Hipertexto como um novo espaço de escrita em sala de aula. Linguagem \& Ensino, Pelotas, v. 4, n. 1, p. 79-111, 2001.

MARCUSCHI, L. A. Da fala para a escrita. Atividades de retextualização. São Paulo: Cortez, 2003.

MARCUSCHI, L. A. Produção textual, análise de gêneros e compreensão. São Paulo: Parábola Editorial, 2008.

MARCUSCHI, L. A \& XAVIER, A. C. Hipertextos e gêneros digitais: novas formas de construção de sentido. 3.ed. São Paulo: Cortez, 2010.

MONDADA, L.; DUBOIS, D. Construção dos objetos de discurso e categorização: uma abordagem dos processos de referenciação. In: CAVALCANTE, M. M.; RODRIGUES, B. B.; CIULLA, A. (org.). Referenciação. São Paulo: Contexto, 2003. p. 17-52.

POSSENTI, S. Língua na mídia. São Paulo: Parábola Editorial, 2009.

SODRÉ, M. Eticidade, campo comunicacional e midiatização. In.: MORAES, D. de (org.). Sociedade Midiatizada. Rio de Janeiro: Mauad, 2006. p. 19-32.

TEDESCO, M. T. O processo de referenciação e a construção do texto argumentativo. 
Universidade Federal do Rio de Janeiro. Rio de janeiro, 2002.

TEDESCO, M. T. Educação a distância: o processo de interação e autoria em EAD na perspectiva da linguagem. In: SIMÕES, D. (org.) Semiótica, linguística e tecnologias de linguagem. Homenagem a Umberto Eco. Dialogarts, 2013. p. 476-493.

Recebido em dia 31 de dezembro de 2018. Aprovado em dia 18 de fevereiro de 2019. 